
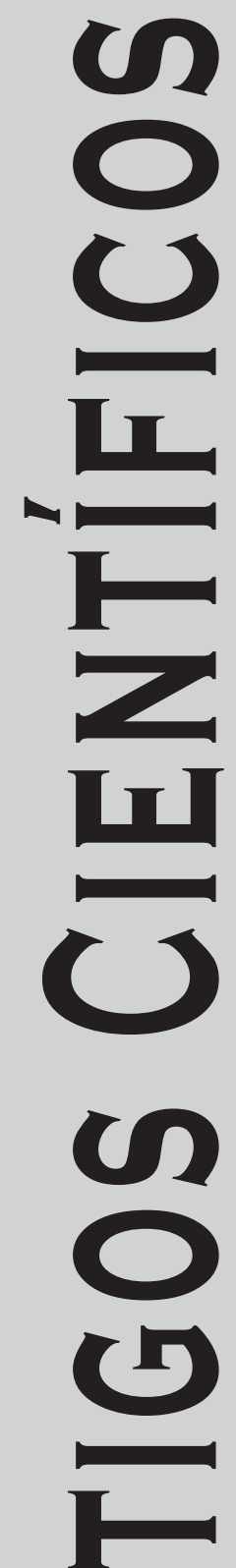
ac

Revista Música Hodie, Goiânia - V.14, 238p., n.1, 2014 


\title{
“Ou Isto ou Aquilo”: a Composição na Educação Musical para Crianças
}

\author{
Viviane Beineke (Universidade do Estado de Santa Catarina, Florianópolis, SC) \\ vivibk@gmail.com \\ Camila Costa Zanetta (Universidade do Estado de Santa Catarina, Florianópolis, SC) \\ camilazanetta@hotmail.com
}

\begin{abstract}
Resumo: Este artigo focaliza a aprendizagem criativa na educação musical, refletindo teoricamente sobre um projeto de composição desenvolvido em uma Oficina de Música para crianças. Neste trabalho, a poesia de Cecília Meireles foi o eixo condutor para a elaboração de poemas musicados. Considerando os espaços de criação enquanto meios que possibilitam o desenvolvimento das capacidades criativas e humanas, o referencial teórico focaliza o processo de composição colaborativa e a possibilidade de convergência de contextos sociais e culturais. Os resultados revelam o engajamento das crianças na produção das composições e as aprendizagens significativas construídas no processo de tomada de decisões musicais. Como fazemos? "Ou isto ou aquilo"?

Palavras-chave: Educação musical; Aprendizagem criativa; Composição musical; Poemas musicados; Oficina de música para crianças.
\end{abstract}

Composition With Poems in Music Education for Children

Abstract: This article focuses on creative learning in music education, reflecting theoretically on a project of composition conducted in a music workshop for children. The work focused on the musicalization of poems by Cecília Meireles. Considering spaces for creation as environments that allow the development of creative and human capacities, the theoretical reference focuses on the collaborative composition process and the opportunity for a convergence of social and cultural contexts. The results reveal children's engagement in the production of compositions and the significant learning constructed in the process of taking musical decisions. How do we do it?

Keywords: Music education; Creative learning, Musical composition; Musicalization of poems; Music workshop for children.

Introdução: breve panorama

Quem sobe nos ares não fica no chão, quem fica no chão não sobe nos ares. Cecília Meireles ${ }^{1}$

A criatividade e os processos de composição no contexto da Educação Musical vêm sendo desenvolvidos como tema de diferentes pesquisas e reflexões. No decorrer do tempo, o ensino e a aprendizagem da música recebem novas contribuições por parte de educadores, pesquisadores e compositores, com o intuito de proporcionar espaços para a criação no processo pedagógico, destacando-se Murray Schafer, John Paynter e Hans-Joachim Koellreutter, dentre outros, que contribuíram trazendo ressignificações ao fazer musical e influenciando gerações posteriores.

Em breve panorama, visualizam-se algumas abordagens que nortearam o ensino de música em diferentes períodos. De modo geral, no século XIX figurava um modelo bastante ligado a concepções individualistas e voltado, principalmente, à formação do virtuose - em decorrência dos modelos europeus de ensino profissionalizante que, em propagação, chegam à América e ao Brasil (BRITO, 2007; FONTERRADA, 2008). No século XX, porém, devido às diversas transformações sociais, ganham espaço novas propostas educacionais.

A transformação das condições de vida no século XX, com a tendência à massificação e à consequente anulação do indivíduo, teria demandado ações educativas de natureza artística, com vias a recuperar a arte criativa e a valorizar o ser. (BRITO, 2007, p. 59) 
Em decorrência das diversas transformações havidas na virada do século XIX para o século XX na sociedade ocidental, observa-se, no início do século XX, o surgimento dessas propostas de natureza artística, ações "capazes de atuar nos âmbitos individual e coletivo, buscando aperfeiçoar as qualidades e a sensibilidade humanas, graças à aproximação com a arte." (FONTERRADA, 2008, p. 96).

No contexto da educação musical, com a "primeira geração" de educadores musicais emergem os "métodos ativos", cujas propostas "descartam a aproximação da criança com a música como procedimento técnico ou teórico, preferindo que entre em contato com ela como experiência de vida.” (FONTERRADA, 2008, p. 177). Embora considerem a interação com a música de modo mais abrangente, tais métodos abordam principalmente a música clássica ocidental ou o folclore, ainda que a produção musical da época estivesse engajada em procedimentos de vanguarda (BRITO, 2007; FONTERRADA, 2008).

Na década de 1950 a 1960 emerge a "segunda geração" de educadores musicais.

Os educadores musicais desse período alinham-se às propostas da música nova e buscam incorporar à prática da educação musical nas escolas os mesmos procedimentos dos compositores de vanguarda, privilegiando a criação, a escuta ativa, a ênfase no som e suas características, evitando a reprodução vocal e instrumental do que denominam 'música do passado'. (FONTERRADA, 2008, p. 179)

Nesse enfoque, trabalhos de composição em sala de aula passam a ser valorizados, considerando processos de criação musical, exploração sonora e escuta ativa como pontos essenciais para a aprendizagem.

Em continuidade, a pesquisa em Educação Musical recebe influências de tais concepções, com crescentes contribuições a respeito dos processos criativos, dentre os quais trabalhos sobre composição e improvisação musical. Atualmente, o fazer musical continua sendo repensado e ressignificado. Podemos citar, nesse âmbito, os trabalhos de Beineke (2008, 2009), Brito (2001, 2003, 2007), Burnard (2002, 2006a, 2006b), França e Swanwick (2002), Gainza (1990) e Swanwick (2003), dentre outros.

Nossa intenção é de colaborar com este artigo para os atuais debates na área ao pensarmos a respeito da composição musical nas aulas de música com crianças, indicando a possibilidade de envolvê-las com a música por meio de suas próprias produções musicais. Com essa finalidade, será descrita uma experiência com crianças na Oficina de Música da UDESC, buscando ampliar reflexões sobre práticas de composição musical em grupo na educação musical.

\section{A composição na Educação Musical: algumas pesquisas e considerações}

Ou isto ou aquilo: ou isto ou aquilo... e vivo escolhendo o dia inteiro! Cecília Meireles

Compor música é tomar decisões musicais: escolher sonoridades, instrumentos, ritmos, experimentar diferentes combinações, decidir quando é hora de repetir, quando é hora de variar ou contrastar elementos musicais. Compor, no contexto educativo em geral e também neste trabalho, é um conceito amplo que engloba desde as pequenas invenções musicais das crianças e seus improvisos espontâneos, até produtos mais elaborados, incluindo a composição de canções e arranjos. 
A composição musical enquanto prática na Educação Musical vem sendo progressivamente valorizada e investigada sob diferentes aspectos: em estudos sobre os seus processos e produtos, sobre a sua avaliação, as concepções e o papel do professor, as perspectivas dos estudantes ou sobre o contexto em que é realizada (BEINEKE, 2008). Como discute Beineke (2008), diferentes concepções guiam os trabalhos com composição no ensino de música. Segundo a autora, propostas muito fechadas, focadas principalmente em aspectos técnicos e sem liberdade para que os alunos experimentem suas ideias, limitam seu desenvolvimento musical, enquanto propostas muito abertas podem deixá-los perdidos. Rusinek (2007) argumenta que as atividades de composição com algum limite definido obrigam os estudantes a aplicarem seus conhecimentos procedurais para desenvolver ideias numa estrutura musical coerente.

Metodologicamente, é importante que o professor encontre o equilíbrio entre estrutura e liberdade ao levar propostas de composição à sala de aula, tendo clareza dos seus objetivos e cuidando para que a atividade não perca o sentido musical nem torne os alunos "engessados" para compor em estruturas fechadas. Segundo Craft et al. (2008), é fundamental à aprendizagem criativa que o professor acompanhe os trabalhos das crianças, para que elas tenham um retorno da sua aprendizagem. Nessa perspectiva, são focalizados o pensamento musical e a compreensão que podem ser desenvolvidos quando os estudantes manipulam materiais musicais e se engajam em processos de criar música.

A inclusão da composição nos planejamentos pedagógico-musicais vem sendo defendida por diversos aspectos. Autores concordam que através da composição os alunos podem manifestar de forma própria suas ideias musicais, revelando como pensam musicalmente (BROPHY, 2005; FRANÇA, 2006; GLOVER, 2000; GOULD, 2006; GROMKO, 2003; MAFFIOLETTI, 2004; MILLER, 2004; PAYNTER, 2000; TAFURI, 2006; WIGGINS, 2003). Além disso, nessas atividades os estudantes confrontam-se com problemas musicais e passam a testar, julgar e validar determinadas ideias (KRATUS, 1994).

As atividades de composição também permitem que os alunos conheçam e desenvolvam a sua própria "voz" musical, que precisa ser reconhecida e valorizada pelos professores (GLOVER, 2000). Glover (2000) considera tal processo como um "pensar em voz alta”, no qual o professor atento pode conhecer particularidades sobre como pensam musicalmente seus alunos, quais suas influências e conhecimentos prévios. Campbell (1998) também faz essa analogia com o "pensar em voz alta”, explicando que essa relação com a música ajuda as crianças em diversos aspectos, em especial na socialização musical.

Nesse sentido, atividades de composição favorecem a conexão entre a produção na escola com os mundos musicais que as crianças vivem fora dela (SWANWICK, 2003) e desenvolvem a capacidade do indivíduo de construir significados a partir de relações que estabelece com as culturas musicais (BARRET, 2003). A composição abre espaço para que os estudantes tragam seus conhecimentos cotidianos para a sala de aula, fundindo-os com os conteúdos formais (SWANWICK, 2003). Assim sendo, o trabalho com a composição permite tanto valorizar as experiências prévias dos alunos, pois possibilita que eles agreguem às suas criações os seus mundos sonoros, quanto perceber seus pensamentos musicais expressos nas suas produções.

Numa perspectiva sociocultural, a composição em sala de aula desloca o foco dos processos e produtos criativos, focalizando o contexto social em que a criatividade emerge: a sala de aula. Nessa perspectiva, são consideradas a gama de práticas culturais, as qualidades de interação e as relações entre os indivíduos e seus ambientes sociais (BURNARD, 2006a). E ainda, como argumentam Bitencourt, Pessôa e Silva (2008), o desenvolvimento da capacidade criadora dos alunos através de atividades de composição pode formar pessoas 
capazes de intervir e transformar a sociedade em que vivem, de maneira crítica e consciente, contribuindo para um desenvolvimento mais igualitário, com menos concentração de poder e controle.

Compreendendo que essa abordagem na Educação Musical enseja muitas possibilidades de construções teóricas e metodológicas, discorreremos sobre a experiência vivenciada na Oficina de Música da UDESC, buscando contribuir com trabalhos nesse campo ao refletir sobre práticas de composição em sala de aula.

\section{A Oficina de Música da UDESC: contextualização}

Ou se tem chuva e não se tem sol, ou se tem sol e não se tem chuva! Cecília Meireles

A Oficina de Música consiste numa ação de extensão da Universidade do Estado de Santa Catarina (UDESC), que busca oportunizar atividades musicais diversas às crianças da comunidade. O projeto objetiva promover aprendizagens musicais significativas, ampliando as ideias de música das crianças e favorecendo a compreensão musical enquanto resultado de reflexões críticas, advindas de fazeres musicais prazerosos e criativos. Constitui também espaço para a atuação e formação de educadores musicais, inserindo acadêmicos do curso de Licenciatura em Música da Universidade no processo de construção e prática de propostas de educação musical ${ }^{2}$. Objetiva ainda favorecer a articulação entre ensino, pesquisa e extensão, produzindo conhecimentos a partir das práticas pedagógicas e retornando esses conhecimentos à comunidade ${ }^{3}$. Atualmente, o projeto é oferecido pelo Grupo de Pesquisa Música e Educação (MUSE), vinculado ao Programa de Pós-Graduação em Música da Universidade do Estado de Santa Catarina (UDESC). ${ }^{4}$

No ano de 2011, período em que ocorreu a experiência que descreveremos aqui, a Oficina de Música era dividida em duas turmas ${ }^{5}$ : uma no período matutino e outra no período vespertino-noturno, atendendo 28 crianças da comunidade. A experiência de composição musical aqui relatada foi realizada com a turma do período matutino, que contava com 13 crianças entre sete e dez anos de idade. Ambas as turmas realizavam encontros semanais de 1 hora e 15 minutos no Laboratório de Educação Musical do Departamento de Música da UDESC. Espaço preparado para o ensino de música, o Laboratório é equipado com diversos instrumentos musicais, como pianos, bateria, flautas doces, xilofones, metalofones, diferentes tambores e também instrumentos construídos com material alternativo. A sala possui também aparelho de som, computador com acesso à internet e projetor data show.

Cada turma era conduzida por uma bolsista e uma estagiária, sob orientação da coordenação do projeto e da professora de estágio supervisionado. O trabalho com as turmas teve início em abril e terminou em dezembro, com uma apresentação musical e com o lançamento do CD Composições entre Nós ${ }^{6}$, que registra composições das próprias crianças e músicas trabalhadas durante o ano com as turmas.

\section{As aulas na Oficina de Música}

Ou se calça a luva e não se põe o anel, ou se põe o anel e não se calça a luva!

Cecília Meireles 
As atividades em sala de aula buscavam articular diversas formas de envolvimento com a música, com ênfase na apreciação, composição e execução. Segundo Swanwick (2003), tal organização curricular favorece o respeito ao discurso musical dos alunos e a suas diferenças, porque cada tipo de atividade desenvolve facetas específicas da sua autonomia, além de permitir que eles se sobressaiam de diferentes formas em sala de aula: tocando, analisando ou compondo música.

Em geral, a partir das atividades de composição musical surgiam ideias a respeito do que poderíamos trabalhar nas atividades de apreciação e execução. Dessa maneira, potencializamos a aprendizagem criativa através de atividades que incentivam a análise e a reflexão sobre as práticas musicais em sala de aula (BEINEKE, 2009). Consequentemente, notamos diversas vezes as conexões feitas pelas crianças entre o que ouviram ou aprenderam a tocar/cantar em sala e as suas composições.

O repertório musical trabalhado nas aulas buscava atender as preferências dos alunos e possibilitar seu contato com materiais e gêneros musicais diversos, ampliando suas ideias de música. Nesse processo, é fundamental o professor atento e dinâmico, que procura ao mesmo tempo valorizar o conhecimento musical cotidiano dos alunos e ampliar suas fronteiras de saberes musicais. Para isso, é imprescindível que o processo metodológico considere características pessoais dos estudantes, seus interesses e necessidades, seus conhecimentos prévios sobre música, além de elementos e valores do contexto sociocultural. Como explica Oliveira (2005), o ensino não necessita ser limitado, podendo levar em conta outras possibilidades de conteúdos, atitudes, valores, habilidades e repertórios que ampliem os horizontes de desenvolvimento dos estudantes, mas respeitando seus valores culturais.

As práticas de composição em grupos foram bastante valorizadas durante o ano, buscando favorecer as interações em sala de aula, a criação colaborativa e a possibilidade de convergência de contextos sociais e culturais, enfim, das relações humanas implicadas no processo da Educação Musical (BRITO, 2001, 2007; KOELLREUTTER, 1997). Os trabalhos em grupos abriam espaço para o diálogo, o debate, a comunicação, a submissão de interesses próprios aos do grupo, a interação com o outro, o respeito às opiniões diversas e os processos de negociação, desenvolvendo, além das capacidades criativas, as capacidades humanas (BEINEKE, 2009; BRITO, 2001, 2007). Com esse ambiente colaborativo, atingíamos o objetivo de construir uma comunidade de prática musical, uma comunidade de aprendizes, com o professor/a nela inserido. A avaliação entre pares era incentivada, de modo que, mediadas pela professora, as crianças assumissem uma posição de plateia crítica que compreende, contribui, colabora e aprende com as composições musicais da turma.

As crianças eram constantemente incentivadas a pensar a respeito dos trabalhos do seu e dos outros grupos, analisando, debatendo, criticando e refletindo sobre os processos e os produtos. Nessa perspectiva, a criatividade é entendida dentro de amplas dimensões éticas, encorajando os alunos a analisarem criticamente as consequências de suas ideias (BEINEKE, 2009).

Essas ideias se aproximam da proposição de Sawyer (2008), de que os estudantes são socializados em comunidades de prática musical na sala de aula, nas quais a classe toda colabora na aprendizagem de cada estudante. Percebe-se então que as crianças entendem a aprendizagem em sala de aula como uma construção coletiva, da qual todos podem participar, dar sugestões e aprender uns com os outros. (BEINEKE, 2011, p. 100)

Nesse processo, Young (2003) explica que o retorno que o professor dá às composições das crianças, respondendo perguntas ou fazendo questionamentos, descrevendo as 
suas composições ou dando sugestões, é essencial no processo da aprendizagem criativa, porque motiva os alunos para os próximos trabalhos. Assim sendo, é necessário que o professor de música participe ativamente, provocando a interação entre as crianças através de discussões sobre os trabalhos produzidos, processo que exige equilibrar a liberdade e a agência da aprendizagem pelas crianças com a estrutura estabelecida pelo professor.

As apresentações musicais, tanto em sala de aula como para familiares e comunidade em geral, também foram importantes no processo pedagógico da Oficina. Como explica Beineke (2009), as apresentações musicais criam elos entre suas vivências cotidianas com música, aproximando suas experiências em sala de aula com o "mundo dos músicos" que as crianças observam nos meios de comunicação, e são socialmente valorizadas. Fazer música, assim, significa também oportunidade de ser reconhecido, de alegrar outras pessoas, de agradar o público, de comunicar, de ser aplaudido.

Algumas músicas do repertório trabalhado e as composições das crianças também foram registradas em um CD, oportunizando o contato dos alunos com processos de gravação musical. Tal atividade, além de registrar o trabalho desenvolvido, também valoriza a produção das crianças, que atribuem novos sentidos à aprendizagem musical. Apresentar e gravar suas produções podem ser fortes mobilizadores da aprendizagem musical, aproximando as crianças do universo musical que elas vivenciam, imaginam, desejam: um universo através do qual elas podem ver suas próprias produções reconhecidas e valorizadas.

Documentar as práticas de sala de aula é essencial nesse processo, porque criamos uma "âncora" que nos ajuda a refletir sobre nossas ações passadas (CRAFT; PAIGE-SMITH, 2010). Segundo Craft e Paige-Smith (2010, p. 39-40), a documentação da prática e da aprendizagem das crianças nos permite compartilhar experiências, ajuda-nos a prever como as crianças aprendem e a identificar suas dificuldades, além de contribuir no planejamento do nosso trabalho. É nessa perspectiva que compartilhamos nossas reflexões sobre o projeto "Poemas musicados: ou isto ou aquilo".

\section{4. "Ou isto ou aquilo": musicando poemas de Cecília Meireles}

Mas não consegui entender ainda qual é melhor: se é isto ou aquilo. Cecília Meireles

Imaginar como as coisas poderiam ser. Está aí um meio pelo qual podemos gerar perguntas, construir hipóteses, experimentar, questionar, avaliar... em suma, criar. Craft (2010) argumenta que o "pensamento de possibilidades" é o núcleo de toda a criatividade das crianças, que podem ser incitadas, nas mais diversas situações, a se perguntar: "e se...”? E se esse poema virasse música? E se fizéssemos assim? Ou como? Você tem uma ideia?

Poemas do livro "Ou isto ou aquilo”, de Cecília Meireles, foram selecionados para a construção de um projeto de composição de canções ${ }^{7}$. Através de seus poemas, Cecília Meireles nos conduz a um universo de imagens sonoras, fantasia e jogos de palavras que transformam o mundo das letras num mundo onírico (SILVA, 2012, p. 5). A autora nos remete ao nonsense, ao inusitado, aos sentimentos da criança, ao prazer lúdico dos sons e das imagens (ROSA, 2009, p. 25).

Cecília traz para a poesia infantil a musicalidade, explorando versos regulares, a combinação de diferentes metros, o verso livre, a aliteração, a assonância e a rima. Os poemas infantis de Cecília Meireles não ficam restritos à leitura infantil, permi- 
tindo diferentes níveis de leitura. A insatisfação com os limites e o desejo de plenitude está presente no poema "Ou Isto Ou Aquilo", que dá título ao seu livro de poesia infantil, publicado em 1964. (CAMARGO, 1998)

Mergulhamos no universo poético de Cecília Meireles no segundo semestre de 2011, quando apresentamos à turma uma proposta de composição em grupos que consistia em compor músicas para poemas da obra "Ou isto ou aquilo". As crianças já haviam realizado em sala atividades de arranjo e criação de jogos cantados, mas musicar poemas era novidade para o grupo. Como exposto por Brito (2007, p. 228), entendemos que "compor em parceria (letra para uma música já existente, ou vice-versa) é, também, possibilidade e exercício de percepção, análise e criação; recurso interessante ao agenciamento de trabalhos de criação com as crianças."

Diversos poemas do livro foram selecionados previamente para serem apresentados às crianças, permitindo que elas escolhessem o texto com o qual gostariam de trabalhar. Os alunos se conheciam desde abril e estavam acostumados ao trabalho em conjunto nas aulas. Assim, pedimos que as crianças se dividissem em quatro grupos para o processo de composição. A ideia de trabalhar em grupos vem ao encontro de Freire (2003, p. 29), quando esclarece que, no grupo, os alunos têm a oportunidade de assumir diversos papéis e exercitar a própria fala, além de defender diversos pontos de vista e refletir sobre eles.

Formados os quatro grupos - um com quatro alunos e os outros com três - espalhamos pelo chão da sala os vários poemas previamente selecionados. Houve, então, o momento de escolha por parte das crianças que, em meio a questionamentos, olhavam e manuseavam as várias possibilidades de texto, liam, reliam e faziam trocas com colegas de outros grupos, até que a decisão sobre qual poema utilizariam fosse tomada. Após esse período de análise dos textos, os quatro poemas selecionados foram: Jogo de Bola, Lua Depois da Chuva, O Cavalinho Branco e Pregão do Vendedor de Lima. Escolhido o material, cada grupo passou a se dedicar à criação de sua música. Eles tiveram em torno de quatro aulas para compor, podendo utilizar o espaço físico da sala de aula e todos os instrumentos musicais e recursos disponíveis.

Quando a proposta de composição foi feita, os alunos também foram informados de que havia a possibilidade de suas músicas serem gravadas no Estúdio do Departamento de Música, fazendo parte do CD do Projeto das Oficinas. Os alunos ficaram bastante empolgados, demonstrando certa euforia ao comentar sobre essa ideia. Discutiam entre si sobre meios de divulgar as futuras composições na internet, na televisão e até mesmo sobre realizarem apresentações musicais com a cobrança de "cachê", pois diziam que se tornariam famosos através da gravação do CD. Em meio à nítida aprovação coletiva sobre o projeto proposto, concordamos em ocupar as aulas seguintes com tal prática.

Assim que a experiência de compor músicas para os poemas foi iniciada pelos grupos, questionamentos, debates, conflitos e escolhas marcaram o decorrer do processo. Algumas crianças tinham dúvidas e conversavam entre si sobre como poderiam começar a composição. Observou-se que, enquanto alguns alunos desejavam primeiramente definir o ritmo de suas músicas, outros preferiam iniciar criando uma melodia para, apenas mais tarde, definir o ritmo que melhor se adequaria à música. Outros, após a escolha do ritmo, passavam a improvisar linhas melódicas.

A improvisação como ponto de partida para a composição é um procedimento observado por Fautley (2004), mas Glover (2000) ensina que cada indivíduo compõe de maneira diferente e que os professores precisam considerar essas diferenças ao conduzir as atividades. Burnard (2000) argumenta que é importante os professores aproveitarem tanto o 
potencial da improvisação como da composição para alcançar uma dimensão social do ensino da música que reconheça o significado das perspectivas das crianças. Desse modo, eles podem encorajar os alunos a discutir e a desenvolver seus próprios valores.

Dos quatro grupos formados, três iniciaram o processo de composição escolhendo o ritmo e, posteriormente, pensando na criação de uma melodia. O outro grupo, por sua vez, começou observando as palavras do poema a as sonoridades sugeridas por elas. Neste caso, notamos que as diversas combinações de vocábulos como "lua, chuva, luva, viúva, uva e guarda-chuva" provocou reações nesse grupo e conduziu os seus integrantes a dirigirem atenção à sonoridade do poema. Assim, passaram a decidir quais instrumentos "combinariam" com aquela sonoridade (chegando a um rápido acordo sobre a escolha do pau de chuva) e a levantar ideias sobre uma melodia cantada.

De acordo com Fialho (2011, p. 121), o poema Lua depois da chuva aborda a musicalidade das rimas e destaca o ritmo dos versos. Outros autores também apontam relações entre música e literatura por meio das imagens acústicas que a linguagem verbal sugere, gerando sensações por meio de rimas e figuras de linguagem, dentre outros. Moura (2011) esclarece que a musicalidade intrínseca à linguagem verbal visa a provocar reações subjetivas e sensoriais no leitor, e para isso são utilizados recursos como onomatopeias, variações tímbricas, pausas expressivas e rimas, por exemplo, sendo esta uma das formas pelas quais música e poesia podem relacionar-se.

Percebemos que os diferentes modos de iniciar o processo de composição musical (pela escolha do ritmo, melodia, instrumentação, entre outros) geraram, inclusive, conflitos entre os componentes dos grupos, já que diversas vezes um aluno discordava de outro por não gostar do modo pelo qual o colega havia sugerido iniciar a composição. Com isso, os grupos se articulavam de maneiras distintas: alguns se encaminhando muito amigavelmente e outros divergindo por não concordarem com o modo de começar a composição. Debatiam também a escolha dos instrumentos.

Durante o processo de composição foi possível acompanhar discussões sobre: as melodias que seriam criadas; os diferentes modos de encaixar metricamente cada palavra do poema na melodia escolhida; a acentuação correta de tempo; o tamanho dos poemas e a verificação do uso ou não de todas as estrofes (para depois selecioná-las); questões de arranjo (como o número de vezes que repetiriam cada estrofe, como iniciariam a música, o que fariam antes da letra cantada, durante e depois, para gerar contrastes no decorrer da obra, instrumentação, definição de forma), entre muitos outros aspectos. Nesse processo, observou-se o engajamento das crianças no fazer musical, enquanto discutiam, refletiam, avaliavam, defendiam, refutavam e validavam ideias musicais implicadas no trabalho.

Algumas crianças disputavam a liderança no seu grupo e queixavam-se quando um dos colegas não participava das discussões. Outras faziam questão de ouvir os colegas e resolver de forma coletiva as questões musicais suscitadas. Esse processo, segundo Freire (2003, p. 29), caracteriza o trabalho de um grupo que passa pelo exercício mútuo do cumprimento das tarefas, na descoberta dos espaços e papeis de cada um e de todos juntos, no exercício da própria fala e do próprio silêncio, na reflexão e na defesa dos seus pontos de vista.

Durante o mês em que foram produzidas as composições também trabalhamos com outras atividades, envolvendo apreciação e execução de diferentes repertórios. Assim, alguns ritmos brasileiros - como ijexá, samba e capoeira - foram explorados, sendo utilizados instrumentos de percussão. Exercícios vocais como aquecimento para as aulas e aspectos técnicos de manipulação dos instrumentos também foram abordados. Essas experiências contribuíram para ampliar as possibilidades técnicas e estilísticas do grupo no trabalho de suas composições. Glover (2000) enfatiza a importância de o professor articular o seu pla- 
nejamento de forma a reconhecer e utilizar, como conteúdos, em suas aulas, materiais e habilidades apresentadas nas composições das crianças, contribuindo com o seu desenvolvimento musical.

Também durante esse processo, distribuímos folhas brancas e pedimos que cada grupo registrasse a letra de sua música e as informações que julgavam importante anotar. Dessa maneira, procuramos introduzir noções de escrita e registro musical, com anotações simplificadas sobre forma e indicações de instrumentos, entre outros aspectos observados nos registros finais dos alunos. Segundo Upitis (2013), esse tipo de atividade possibilita o desenvolvimento de uma abordagem criativa da notação, expandindo os horizontes musicais das crianças.

As quatro composições originadas dos poemas resultaram em dois sambas, um rap e uma canção ${ }^{8}$. Durante o processo de criação dessas músicas, todos os grupos estiveram plenamente envolvidos na resolução de diversos problemas musicais.

A experiência do grupo que trabalhou com o poema Pregão do Vendedor de Lima, constituído apenas por meninos, traz alguns exemplos desses processos de decisão musical. Os integrantes do grupo já haviam selecionado o ritmo da capoeira para o acompanhamento, mas nenhum deles fazia questão de cantar nem de compor uma melodia para a letra do poema. Diziam não gostar de cantar e ter vergonha de fazê-lo ante a turma. Essa situação se manteve por alguns encontros até que, juntos, optaram por criar um rap com instrumentos de percussão e utilizar a voz falada. Com essa escolha, solucionaram o problema que tinham em relação ao uso da voz cantada.

Por sua vez, o grupo de meninas que estava musicando o poema Lua depois da chu$v a$ foi avisado, na semana anterior à apresentação, que não poderia contar com a presença de uma das componentes naquela data. A integrante que precisaria faltar à apresentação era responsável, juntamente com outra colega, por tocar piano (uma executando a melodia e outra a harmonia). Para solucionar o problema, outra participante do grupo propôs aprender a melodia no piano, em vez de continuar responsável pela execução do pau-de-chuva. Foi então que um aluno de outro grupo se ofereceu para tocar pau-de-chuva, dizendo que poderia acompanhar as meninas no dia da apresentação. Desse modo, o problema com o qual se depararam foi solucionado, mantendo-se a instrumentação inicial pensada para a obra.

Para Berkley (2004), atividades de composição em contextos pedagógicos funcionam como poderosa ferramenta para resolver problemas musicais, exigindo dos estudantes o desenvolvimento de habilidades de hipótese e verificação. Esse tipo de envolvimento foi verificado nos grupos quando experimentavam, verificavam, validavam ou questionavam os resultados. Os problemas eram resolvidos pelos alunos coletivamente, integrando outros saberes que eles traziam de suas vivências cotidianas, como no caso do rap. Perceberam-se também atitudes solidárias e amigáveis nesse processo de solução de problemas, como no caso do menino que se dispôs a ajudar as colegas para suprir o desfalque na instrumentação e no arranjo durante a apresentação.

Dessa forma, o trabalho criativo ultrapassa o objetivo de criar algo novo para os alunos ou a aplicação de conhecimentos musicais adquiridos, pois mais do que os produtos elaborados em aula, o foco são as aprendizagens colaborativas, de seres humanos que se relacionam fazendo música, que se escutam e que aprendem uns com os outros. (BEINEKE, 2009, p. 246)

Refletindo sobre o processo, observamos que os alunos estiveram engajados no processo de composição, analisando relações entre a letra e a melodia, instrumentação, expressividade, forma e diversos apontamentos musicais. Também observamos atitudes colabo- 
rativas entre as crianças, envolvimento, submissão de interesses próprios aos do grupo e a solução coletiva de problemas. Nesse sentido, os resultados do projeto dialogam com as pesquisas supracitadas, conectando teorias e práticas de educação musical, argumentando pelo potencial desenvolvimento de capacidades criativas e humanas no decorrer do processo de composição colaborativa.

\section{Considerações finais}

Não sei se brinco, não sei se estudo, se saio correndo ou fico tranquilo.

Cecília Meireles

Refletir sobre nossas práticas educativas permite construir pontes entre nossas experiências e os referenciais que as fundamentam, criando um movimento entre teorias e práticas que acionam questionamentos e reconstruções teórico-metodológicas. Segundo Paige-Smith e Craft (2010, p. 31), reflexões sobre como percebemos as experiências das crianças também são necessárias, pois permitem desenvolver nossa percepção e compreender melhor as perspectivas das crianças sobre o processo educativo. Segundo as autoras, é fundamental que os adultos observem sensivelmente o que as crianças estão fazendo e como exploram o mundo, construindo modos de dialogar com elas de forma aprofundada.

Os adultos que estejam respondendo de maneira sensível, e que se envolvam no desenvolvimento de uma experiência contínua de aprendizagem, fomentam a aprendizagem e o desenvolvimento das crianças de modo que atende os próprios interesses da criança e suas perspectivas, além de dar espaço para ideias e possibilidades que surjam desse diálogo. (CRAFT; PAIGE-SMITH, 2010, p. 34-35)

No processo de compor e ensaiar suas peças, as crianças definiram questões relativas à forma, à dinâmica e à textura, entre outros aspectos que elas foram resolvendo entre si, possibilitando um refinamento musical. Ao mesmo tempo que criavam, elas também se preocupavam com o produto que seria apresentado, fazendo emergir o empenho pessoal para o aprendizado de questões técnicas, evidenciando o desejo de aprender para uma melhoria da performance. Assim, a técnica dos instrumentos também estava sendo trabalhada musicalmente, através do engajamento das crianças na interpretação de suas composições. Como explicam Burnard et al. (2013, p. 68), no ato e no processo da performance musical as crianças podem desenvolver habilidades para um trabalho colaborativo compartilhado, empatia musical, comunicação expressiva, independência de pensamento e curiosidade, desenvolvendo a criatividade musical também na performance.

Por sua vez, o trabalho colaborativo melhora a comunicação, ensejando o diálogo, interações com o outro, o respeito ao lidar com opiniões divergentes, negociações, aceitação e resolução de problemas coletivamente. Tais ações foram observadas no decorrer do processo de composição na Oficina, gerando a construção de atitudes de respeito ao outro, de acolhimento, de reconhecimento de diferenças. Valorizamos as relações humanas que os alunos vivenciam em sala de aula, construindo a aprendizagem socialmente: a educação enquanto compromisso entre pares e outras pessoas. Tal enfoque amplia as concepções que focalizam o desenvolvimento individual dos estudantes ou o estudo de processos e produtos criativos.

No contexto da Oficina, compor músicas para poemas parece ter sido uma estratégia metodológica que equilibrou limites e liberdade na orientação dos trabalhos das crian- 
ças. Ao mesmo tempo que a poesia sugere uma métrica, um ritmo ou um caráter, os poemas de Cecília Meireles trazem um universo criativo que favorece a imaginação, a invenção e o prazer estético. Além disso, canções fazem parte do cotidiano das crianças, o que também trouxe um elemento de familiaridade na construção dos trabalhos, tornando a proposta clara o suficiente para que elas trabalhassem com autonomia.

Considerando o trabalho de composição como processo significativo para as crianças, argumentamos - com sustentação teórica e prática - que tal experiência deve ser valorizada no ensino e na aprendizagem da música. Reforçamos esse pensamento porquanto criar em grupo enseja às crianças a possibilidade de construir coletivamente conhecimentos musicais e formar sujeitos críticos e reflexivos em relação ao universo musical em que se encontram inseridos.

\section{Notas}

1 Trecho do poema “Ou isto ou aquilo”, de Cecília Meireles, publicado pela primeira vez em 1964. No decorrer do artigo são apresentados outros trechos do mesmo poema.

2 Os acadêmicos atuam no projeto como estagiários ou como bolsistas de extensão.

3 Várias publicações acadêmicas referentes ao trabalho desenvolvido na Oficina já foram realizadas, como alguns artigos e uma dissertação de mestrado. Dentre as comunicações mais recentes em congressos, figuram: "A composição musical de crianças: um olhar para a construção de ideias de música em sala de aula” (PINHEIRO MACHADO; BEINEKE, 2012); "Compondo com Cecília Meireles: relato de uma experiência na Oficina de Música” (ZANETTA; SILVA; BEINEKE, 2012) e "Uma festa agitada: relato de atividade de composição em oficina de música para crianças” (SENS; BEINEKE, 2013). A dissertação de mestrado, por sua vez, foi intitulada “"No nosso mundo a gente inventa': um estudo sobre a aprendizagem criativa em uma oficina de música para crianças” (PINHEIRO MACHADO, 2012).

4 No ano de 2011 o programa NUPEART - Núcleo d Educação e Arte foi responsável por oferecer a Oficina de Música. Por esse motivo, artigos anteriores o mencionam.

5 Equipe da Oficina em 2011: Regina Finck Schambeck e Viviane Beineke (coordenadoras da Oficina de Música); Gabriela Flor Visnadi e Silva (orientadora de estágio); Camila Costa Zanetta e Vilmar Uhlig Júnior (bolsistas de extensão) e Ana Carolina Miranda e Marília F. G. de Oliveira (estagiárias).

${ }^{6}$ As gravações foram realizadas no estúdio do Departamento de Música da UDESC, trabalho desenvolvido com a colaboração de Luiz Sebastião Juttel (mixagem) e Mateus Mira Bittencourt (mixagem e masterização) e produção de Gabriela Flor Visnadi e Silva, Pedro Pereira Cury e Viviane Beineke.

7 Musicar um poema, segundo Oliveira (apud Moura, 2011), consiste em associar música e poesia; quando o poema constitui suporte para a composição musical, chama-se "colagem".

${ }^{8}$ Ver clipe do trabalho em: <http://vimeo.com/33782945>.

\section{Referências}

BARRET, Margaret S. Freedoms and constraints: constructing musical worlds through the dialogue of composition. In: HICKEY, Maud (Ed.). Why and how to teach music composition: a new horizon for Music Education. Reston: MENC - The National Association for Music Education, 2003, p. 3-27.

BEINEKE, Viviane. Aprendizagem criativa na escola: um olhar para a perspectiva das crianças sobre suas práticas musicais. Revista da ABEM, Londrina, v.19, n.26, p. 92-104, jul/dez. 2011. Disponível em: <http://www.abemeducacaomusical.org.br/Masters/revista26/revista26_artigo8.pdf>.

. Processos intersubjetivos na composição musical de crianças: um estudo sobre a aprendizagem criativa. 2009. 289 f. Tese (Doutorado em Música) - Universidade Federal do Rio Grande do Sul, Porto Alegre, 2009. Disponível em: <http://hdl.handle.net/10183/17775>. 
. A composição no ensino de música: perspectivas de pesquisa e tendências atuais. Revista da ABEM, Porto Alegre, v.20, n.20, p. 19-32, set. 2008. Disponível em: <http://www. abemeducacaomusical.org.br/Masters/revista20/revista20_artigo2.pdf>.

BERKLEY, Rebecca. Teaching composing as creative problem solving: conceptualizing composing pedagogy. British Journal of Musical Education, Cambridge, v.21, n.3, p. 239-263, 2004.

BITENCOURT, Rafael Linhares; PESSÔA, Priscilla Paraíso; SILVA, José Alberto Salgado e. A metodologia de pesquisa-ação em práticas de composição no ensino de música. In: ENCONTRO NACIONAL DA ABEM, 17., 2008, São Paulo. Anais... São Paulo: UNESP, 2008. p. 1-6.

BRITO, Teca Alencar de. Por uma educação musical do Pensamento: novas estratégias de comunicação. 2007, 288f. Tese (Doutorado em Comunicação e Semiótica) - Pontifícia Universidade Católica de São Paulo, São Paulo, 2007.

. Música na educação infantil: propostas para a formação integral da criança. 2. ed. São Paulo: Fundação Peirópolis, 2003. 204p.

. Koellreutter educador: o humano como objetivo da educação musical. São Paulo: Fundação Peirópolis, 2001. 185p.

BROPHY, Timothy S. A longitudinal study of selected characteristics of children's melodic improvisations. Journal of Research in Music Education, v.53, n.2, p. 120-133, Summ 2005.

BURNARD, Pamela et al. Becoming Performers: Creating Participatory Spaces Collaboratively. In: BURNARD, Pamela; MURPHY, Regina (Ed.). Teaching Music Creatively. Abingdon: Routledge, 2013. p. 55-68.

BURNARD, Pamela. The individual and social worlds of children's musical creativity. In: MCPHERSON, Gary. The child as musician: a handbook of musical development. Oxford: Oxford University Press, 2006a. p. 352-374.

. Understanding children's meaning-making as composers. In: DELIÈGE, I.; WIGGINS, G. A. Musical creativity: multidisciplinary research in theory and practice. New York: Psychology Press, 2006b. p. 111-133.

. Investigating children's meaning-making and the emergence of musical interaction in group improvisation. British Journal of Music Education, Cambridge, v.2, n.19, p. 157-172, 2002.

CAMARGO, Luís. A Poesia infantil no Brasil. Disponível em: <http://www.blocosonline. com. br/literatura/prosa/artigos/art021.htm>. Acesso em: 16 nov 2013.

CAMPBELL, Patricia Shehan. Songs in their heads: music and its meaning in children's lives. Oxford: Oxford University Press, 1998. 264p.

CRAFT, Anna. A criatividade e os ambientes da educação infantil. In: PAIGE-SMITH, Alice; CRAFT, Anna; e colaboradores. O Desenvolvimento da Prática Reflexiva na Educação Infantil. Trad. Vinícius Figueira. Porto Alegre: Artmed, 2010. p. 120-135.

CRAFT, Anna. PAIGE-SMITH, Alice. O que é refletir sobre a prática? In: PAIGE-SMITH, Alice; CRAFT, Anna; e colaboradores. O Desenvolvimento da Prática Reflexiva na Educação Infantil. Trad. Vinícius Figueira. Porto Alegre: Artmed, 2010. p. 33-46.

CRAFT, Anna et al. Possibility thinking with children in England aged 3-7. In: CRAFT, Anna; CREMIN, Teresa; BURNARD, Pamela (Eds.). Creative learning 3-11: and how to document it. Sterling: Trentham Books Limited, 2008. p. 63- 73. 
FAUTLEY, M. Teacher intervention strategies in the composing processes of lower secondary school students. International Journal of Music Education, v.22, n.3, p. 201-218, 2004.

FIALHO, Paloma de Fátima França. O discurso pedagógico na obra infantil de Cecília Meireles. 2011. 131f. Dissertação (Mestrado em Letras) - Faculdade de Ciências e Letras de Assis, Universidade Estadual Paulista, Assis, 2011.

FONTERRADA, Marisa Trench de Oliveira. De tramas e fios: um ensaio sobre música e educação. 2. ed. São Paulo: Editora Unesp, 2008. 364p.

FRANÇA, Cecília Cavalieri. Do discurso utópico ao deliberativo: fundamentos, currículo e formação docente para o ensino de música na escola regular. Revista da ABEM, Porto Alegre, v.15, n.15, p. 67-79, set. 2006.

FRANÇA, Cecília Cavalieri; SWANWICK, Keith. Composição, apreciação e performance na educação musical: teoria, pesquisa e prática. Em Pauta, Porto Alegre, v.13, n.21, p. 5-41, 2002.

FREIRE, Madalena. O que é um grupo? In: FREIRE, Madalena (Org.). Grupo - indivíduo, saber e parceria: malhas do conhecimento. São Paulo: Espaço Pedagógico, 2003. p. 29-38.

GAINZA, Violeta Hemsy de. A improvisação musical como técnica pedagógica. Cadernos de estudo: Educação Musical, São Paulo, n.1, 1990. Disponível em: <http://www.atravez.org.br/ ceem_1/improvisacao_musical.htm>. Acesso em: 15 nov 2013.

GLOVER, Joanna. Niños compositores 4-14 años. Trad. Orlando Musumeci. Barcelona: Grao Publicaciones, 2000. 164p.

GOULD, Elizabeth. Dancing composition: pedagogy and philosophy as experience. International Journal of Music Education, v.24, n.3, p. 197-207, 2006.

GROMKO, Joyce Eastlund. Children composing: inviting the artful narrative. In: HICKEY, Maud (Ed.). Why and how to teach music composition: a new horizon for Music Education. Reston: MENC - The National Association for Music Education, 2003. p. 69-90.

KOELLREUTTER, Hans-Joachim. O ensino da música num mundo modificado. Cadernos de estudo: Educação Musical, Belo Horizonte, $\mathrm{n}^{\circ}$ 6, 1997. Disponível em: <http://www.atravez.org. br/ceem_6/mundo_modificado.htm>. Acesso: em 10 out 2013.

KRATUS, John. The ways children compose. In: LEES, Heath (Ed.). Musical Connections: Tradition and Change. Tampa: Proceedings of the $21^{\text {st }}$ World Conference of the International Society for Music Education, 1994. p. 128-141.

MAFFIOLETTI, Leda de Albuquerque. Diferenciações e integrações: o conhecimento novo na composição musical infantil. 2004. 248 f. Tese (Doutorado em Educação) - Faculdade de Educação, Universidade Federal do Rio Grande do Sul, Porto Alegre, 2004.

MEIRELES, Cecília. Ou isto ou Aquilo. 6. ed. Rio de Janeiro: Nova Fronteira, 2002.

MILLER, Beth Ann. Designing compositional tasks for elementary music classrooms. Research Studies in Music Education, n.22, p. 59-71, 2004.

MOURA, Verônica de Fátima Gomes de. A Canção no Contexto das Relações da Poesia com a Música. In: CONGRESSO INTERNACIONAL DA ABRALIC, 12., 2011, Curitiba. Anais... Curitiba: ABRALIC, p. 1-9, 2011. Disponível em: <http://www.abralic.org.br/anais/cong2011/ AnaisOnline/resumos/TC0536-1.pdf>. Acesso em: 10 nov 2013.

OLIVEIRA, Alda. Music teaching as culture: introducing the pontes approach. International Society for Music Education, v.23, n.3, p. 205-216, 2005. 
PAIGE-SMITH, Alice; CRAFT, Anna. Parte I: O que é preciso para que sejamos profissionais que refletem sobre a prática na educação infantil? In: PAIGE-SMITH, Alice; CRAFT, Anna; e colaboradores. O Desenvolvimento da Prática Reflexiva na Educação Infantil. Trad. Vinícius Figueira. Porto Alegre: Artmed, 2010. p. 31-32.

PAYNTER, John. Making progress with composing. British Journal of Music Education, Cambridge, v.17, n.1, p. 5-31, 2000.

PINHEIRO MACHADO, Cecília Marcon. "No nosso mundo a gente inventa": um estudo sobre a aprendizagem criativa em uma oficina de música para crianças. 2013. 134f. Dissertação (Mestrado em Música) - Universidade do Estado de Santa Catarina, Florianópolis, 2013.

ROSA, Maria Fernanda Vieira. O sentido da poesia na educação infantil: a função social e algumas possibilidades pedagógicas. 2009. 68f. Trabalho de conclusão de curso (Graduação em Pedagogia) - Universidade do Estado da Bahia, Salvador, 2009. Disponível em: < http://www. uneb.br/salvador/dedc/files/2011/05/Monografia-MARIA-FERNANDA-VIEIRA-ROSA.pdf>.

RUSINEK, Gabriel. Students perspectives in a collaborative composition project at a Spanish secondary school. Music Education Research, London, v.9, n.3, p. 323-335, 2007.

SAWYER, R. Keith. Learning music from collaboration. International Journal of Educational Research, v.47, p. 50-59, 2008.

SILVA, Camila V. Ramos da. Ou Isto ou Aquilo: uma breve análise da literatura infantil de Cecília Meireles. Revista Anagrama: Revista Científica Interdisciplinar da Graduação, Ano 6, N. 1, Set/Nov 2012. Disponível em: <http://www.revistas.univerciencia.org/index.php/anagrama/article/viewFile/8271/7680> Acesso em: 16/11/2013.

SWANWICK, Keith. Ensinando música musicalmente. Trad. Alda Oliveira e Cristina Tourinho. São Paulo: Moderna, 2003. 128p.

TAFURI, Johannella. Processes and teaching strategies in musical improvisation with children. In: DELIÈGE, Irène; WIGGINS, Geraint A. (Eds.). Musical Creativity: multidisciplinary research in theory and practice. New York: Psychology Press, 2006. p. 134-157.

UPITIS, Rena. Celebrating children's invented notations. In: BURNARD, Pamela; MURPHY, Regina (Ed.). Teaching Music Creatively. Abingdon: Routledge, 2013. p. 111-128.

WIGGINS, Jackie. A frame for understanding children's compositional processes. In: HICKEY, Maud (Ed.). Why and how to teach music composition: a new horizon for music education. Reston: MENC - The National Association for Music Education, 2003. p. 141-165.

YOUNG, Susan. Time-space structuring in spontaneous play on educational percussion instruments among three- and four-year-olds. British Journal of Music Education, Cambridge, v.20, n.1, p. 45-59, 2003.

Viviane Beineke - Mestre e doutora em Música/Educação Musical pela Universidade Federal do Rio Grande do Sul. Professora do Curso de Licenciatura em Música e do Programa de Pós-Graduação em Música da Universidade do Estado de Santa Catarina. Publicou artigos em importantes revistas nacionais e internacionais. Desenvolve pesquisas sobre formação, processos e práticas em educação musical, com ênfase na aprendizagem criativa.

Camila Costa Zanetta - Aluna do Mestrado em Música na Universidade de São Paulo e Licenciada em Música pela Universidade do Estado de Santa Catarina. Foi bolsista de extensão durante dois anos na Oficina de Música da UDESC. Atualmente, é bolsista de pesquisa FAPESP sob orientação da Prof. a Dra. Teca Alencar de Brito. Investiga as contribuições das experiências de improvisação musical às crianças, abarcando a interdisciplinaridade entre Música e Teatro em jogos de improvisação. 